\title{
Application of response surface methodology (RSM) to the prediction of the service life of cutters used in milling super-alloy Waspaloy
}

\author{
Shao-Hsien Chen ${ }^{1}$ and Yu-Lun $\mathrm{Ho}^{2}$ \\ ${ }^{1}$ The Graduate Institute of Precision Manufacturing, National Chin-Yi University of Technology, Taichung, Taiwan \\ ${ }^{2}$ Department of Mechanical Engineering, National Chin-Yi University of Technology, Taichung, Taiwan
}

\begin{abstract}
Nickel-based materials are widely used in making engine parts, compressor rotors and energy production. Nickel-based materials are resistant to corrosive conditions, and have a high strength in extreme temperatures. They also feature satisfactory mechanical properties in extreme heat. The use of these nickel-based super-alloys is on the rise every day as they have been widely used in military and civilian aeronautical industries in recent years. For this reason, it was the intention of this study to do optimised cutting experiments on Waspaloy in order to identify the significant factors which have impact on the tool life of cutting tools using the response surface methodology (RSM) in regression analysis. Several factors that had significant impact on the machining tools' life were found in the results, including machining speed, depth, and feed rate. Finally, a regression analysis was adopted to establish a formula for calculating the service life of cutting tools. It was found that the minimum wear was achieved with the cutting speed at $V=33.21 \mathrm{~m} / \mathrm{min}$, cutting depth at $d p=0.0367 \mathrm{~mm}$ and feed per tooth at $F t=0.367 \mathrm{~mm} /$ tooth.
\end{abstract}

KEYWORDS Super-alloy; Waspaloy; milling; tool life

CONTACT Shao-Hsien Chen@e6036@ncut.edu.tw

Received 9 December 2017

\section{Introduction}

Most difficult-to-machine materials in modern days are based on titanium and nickel. Titanium-based materials are used for engine parts, such as fan blades, diffusor cases, engine components for jet engines and hip joints. Their strength drops significantly when the temperature exceeds $400^{\circ} \mathrm{C}-500^{\circ} \mathrm{C}$. Nickel-based materials, on the other hand, are mainly used in combustors, high-pressure turbines, and high-pressure compressors. For the purpose of this study (Foster and Aucote, 1986; Thangaraj and Weinmann, 1992), a series of machining experiments were conducted on Waspaloy, a type of nickel-based super-alloy (Ozturk et al., 2016).

Waspaloy exhibits good tensile strength, fatigue resistance, creep strength, corrosion resistance, outstanding weld-ability, and satisfactory ductility even under extreme heat, making it perfect for an environment where extreme temperatures and loads are common. However, heatresistant super-alloys are considered some of the most difficult materials to be machined for the following reasons:

\section{(1) Work hardening}

Chipping at the interface between the cutter and base material and increased wearing at the edge is common. The metal shavings are tough and virtually unbreakable, and the shavings are difficult to be chipped (Kear et al., 1970; Komanduri and Schroeder, 1986).
(2) Low thermal conductivity

Heat is generated during the machining of regular steel. Some of the heat generated is usually brought away by metal shavings. However, this is not the case for thermal-resistant super-alloys. The heat generated tends to accumulate on the tool and the super-alloy base material due to the poor thermal conductivity of the base material. In addition, the thermal-resistant super-alloys feature high yields and tensile strengths. They create enormous cutting resistance and in turn cause high pressure and temperature at the edge of the cutter and ultimately the plastic deformation of the tool.

(3) Affinity between the machining tools and the thermalresistant super-alloys

In scenarios of discontinued cutting such as milling, the edge of cutter and shavings sometimes melts, and the melted materials are embedded in the workpiece, causing a larger impact or even chipping on the tool (Xue and Chen, 2011).

Wagner et al. (2014) heated titanium alloy Ti-5553 using semi-circular inductors. In their experiment, the cutting force was found $13 \%$ lower when machining at $500^{\circ} \mathrm{C}$ than at room temperature, and $34 \%$ lower when the temperature was increased to $650^{\circ} \mathrm{C}-750^{\circ} \mathrm{C}$, as shown in Figure 1. It is clear that the preheating with an addition of heat source made quite a difference in machining. The performance of the 
cutting tools chosen is very important to a machining process. The wearing of tools has a direct impact on the machining efficiency and accuracy, which makes the accurate prediction of the cutting tools' service life ever so important (Akhtar et al., 2014; Bhatt et al., 2010; Obikawa et al., 2012). Response surface methodology (RSM) is applicable to uncoated carbide cutters. Dry machining and end milling cutters are used for establishing the tool life of cutting tools made of Ti-6AL-4V. The tool life model established suggests that, at $100 \%$, cutting condition entailing machining speed, depth of cut, and feed rate should have $70 \%, 27 \%$, and $37 \%$ of impact on the cutters, respectively (Turnad et al., 2008).

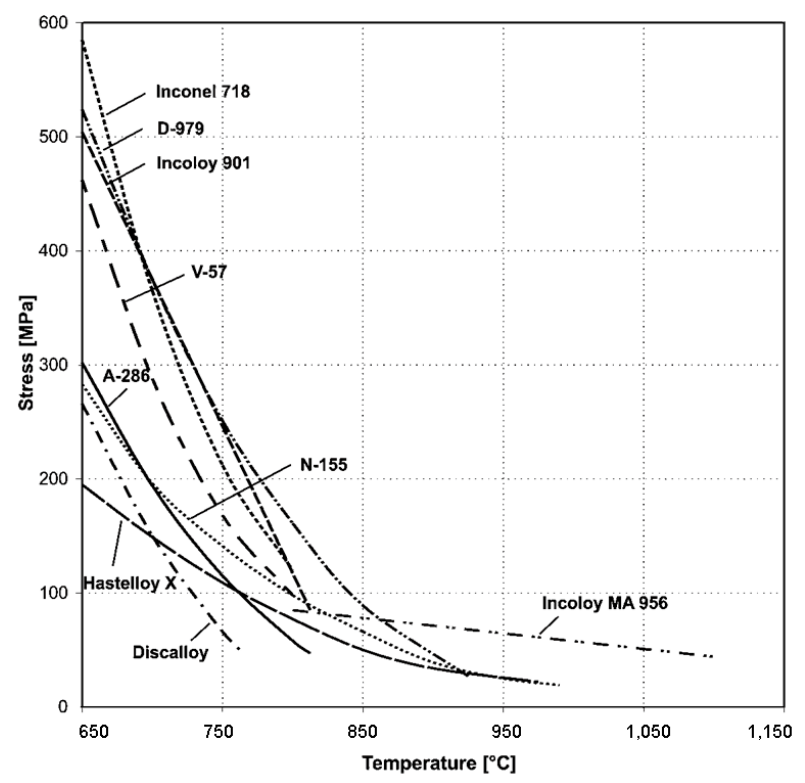

Figure 1. Tensile properties and stress of age-hardenable super-alloys (Carpenter Technology Corporation, 2009).

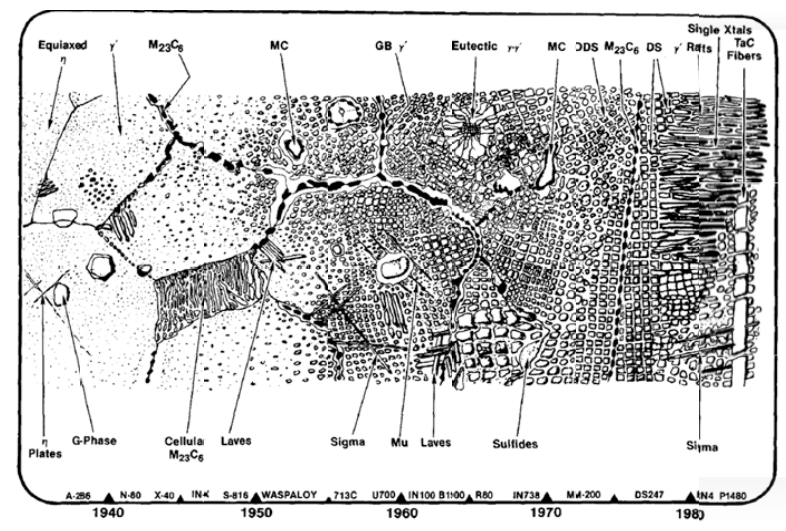

Figure 2. Flow and fracture behaviour in the grain boundary of Waspaloy (Sims and Hagel, 1972: p.12).

RSM is a statistical method that helps investigate the relationships between multiple independent variables and single response variables in an unknown function. It is a combination of an experiment design and a regression analysis. The response values required and the corresponding input parameter positions are experimentally obtained in the defined input parameter space. In general, RSM is graphically presented to provide an effective method to solve issues such as optimisation of the design of products, the production process and the system. Nonetheless, there are two constraints on its application. The first one is works for continuous systems as it is assumed that the measurement scale is continuous for all response values and independent variables; the second one is that independent variables influencing the system are measurable (controllable and non-controllable variables). It is possible to effectively determine the optimised values of experiment or operation variables with assumptions of RSM and constraints on application systems (Chomsamutr and Jongprasithporn, 2012; Hadzley et al., 2016; Reddy et al., 2011; Saedona et al., 2012).

\section{Material properties}

Vacuum induction melting has been introduced to the application for many nickel-based materials in recent years. Once done, the Inconel-718 and Waspaloy are extruded and annealed for homogenisation. The purpose is to eliminate the segregation or ribbon structure in the crystalline structure of material. The super-alloy is an austenite structure with a face-centred cubic (FCC) arrangement featuring resistance to heat. The crystalline phase is shown in Table 1 and Figure 2.

Table 1. Waspaloy alloy structure.

\begin{tabular}{|l|l|}
\hline \multicolumn{2}{|c|}{ Structure of Waspaloy } \\
\hline \multicolumn{1}{|c|}{ Form } & \multicolumn{1}{c|}{ Type } \\
\hline Main Phase & $\gamma:$ FCC matrix of Ni \\
\hline Minor Phases & $\gamma^{\prime}: \mathrm{Ni}_{3} \mathrm{Al}$ or $\mathrm{Ni}_{3} \mathrm{Ti}(\mathrm{FCC})$ \\
& $\gamma^{\prime \prime}: \mathrm{Ni}_{3} \mathrm{Nb}$ (Tetragonal $\left.\mathrm{BCT}\right)$ \\
& $\delta: \mathrm{Ni}_{3} \mathrm{Nb}(\mathrm{Orthorhombic})$ \\
& $\eta: \mathrm{Ni}_{3} \mathrm{Ti}(\mathrm{HCP})$ \\
\hline Carbides & $\mathrm{MC}, \mathrm{M}_{23} \mathrm{C}_{6}, \mathrm{M}_{6} \mathrm{C}$ and $\mathrm{M}_{7} \mathrm{C}_{3}$ \\
\hline
\end{tabular}

Waspaloy, among all nickel-based materials, is a precipitation strengthening alloy. Its primary precipitation strengthens in the $\gamma^{\prime}$ phase. Waspaloy is different from Inconel-718. In the $\gamma^{\prime}$ phase, it is composed of Ti and Al. In addition, Waspaloy contains carbon, boron and zirconium, which are strengthening elements in the crystalline structure. In the $\gamma^{\prime}$ phase, the precipitates of $\mathrm{Ni}_{3} \mathrm{Al}_{\text {or }} \mathrm{Ni}_{3} \mathrm{Ti}$ improve the bonding between elements. The strength of Waspaloy comes mostly from the coherent hardening of precipitates during the $\gamma^{\prime}$ and $\gamma^{\prime \prime}$ phases, where the $\gamma^{\prime \prime}$ phase is the primary strengthening phase. By controlling the parameters of the hot isostatic pressing (HIP) process, the massive and even distribution is achieved in the $\gamma^{\prime \prime}$ phase. Also, the $\delta$ phase melts due to the temperature rise from the 
HIP, which indirectly increases the quantity of precipitates in the strengthening phase and in turn the mechanical strength of Waspaloy (Che-Haron et al., 2001; Haldipur and Bruce, 2006; Jaffery and Mativenga, 2012; Stanke and Kino, 1984).

When looking at the figure of time-temperaturetransformation (TTT) of nickel-based super-alloy as shown in Figure 3, the precipitation temperature in the $\delta$ phase is higher than that in the $\gamma^{\prime}$ phase, and the long-term temperature change in $\delta$ phase and $\gamma^{\prime}$ phase is smaller than the one in the $\gamma^{\prime \prime}$ phase. The main reason is that when under an extreme temperature, the high heat creates the resistance to creep deformation in the $\gamma^{\prime}$ phase. The quantity formed in the $\gamma^{\prime}$ phase depends on the chemical composition and temperature. As shown in Figure 4, there are FCCs and randomly distributed atoms of solid solution in the $\gamma$ phase, whereas the $\gamma^{\prime}$ phase consists of the original cubic lattices where nickel atoms are concentrated at the centre while the aluminium or titanium atoms are scattered at the corners.

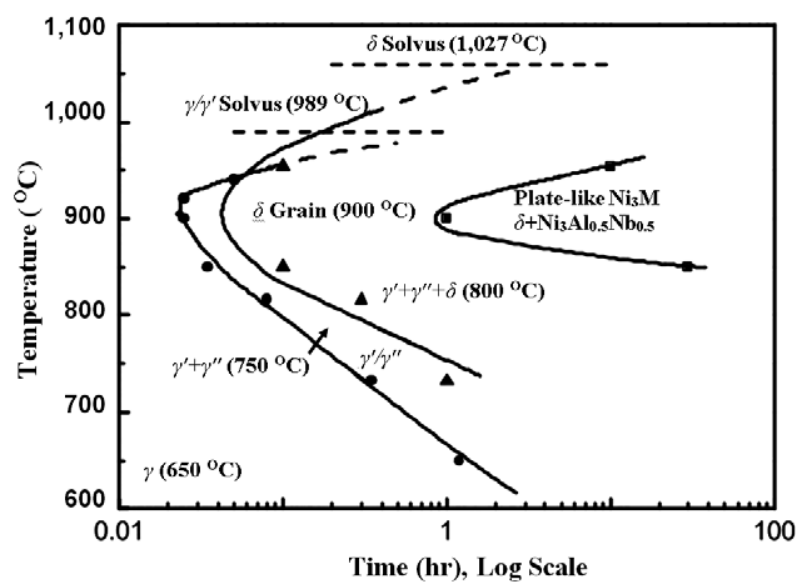

Figure 3. TTT of nickel-based super-alloy (McDevitt, 2013).

Waspaloy is a super-alloy developed in recent years. It features: (1) solid-soluble strengthening elements, such as $\mathrm{Mo}, \mathrm{Co}, \mathrm{Cr}$ and $\mathrm{V}$, as local lattice strains are created at $\mathrm{Ni}-\mathrm{Fe}$ base for material strengthening by the difference in atomic radius and base material, (2) precipitate strengthening elements, such as $\mathrm{Al}, \mathrm{Ti}, \mathrm{Nb}$ and $\mathrm{Ta}$, which allow the creation of integrated, sequential A3B intermetal compound. For example, a strengthening phase $\left(\gamma^{\prime}\right)$ such as $\mathrm{Ni}_{3}(\mathrm{Al}, \mathrm{Ti})$ provides effective strengthening to the alloy, thus enabling greater high-temperature strength than iron and cobalt-based thermal resistant alloys, and (3) crystal boundary strengthening elements, such as B, Zr, $\mathrm{Mg}$, and rare earth elements, which serve to improve the properties of alloy at a high temperature. Table 2 gives the composition of Waspaloy, indicating a typical nickel-based material. As a result, it exhibits hardening precipitation, good material affinity, and low thermal conductivity coefficient (Bhadeshia, 2012; Haldipur et al., 2003; Li et al., 2003).

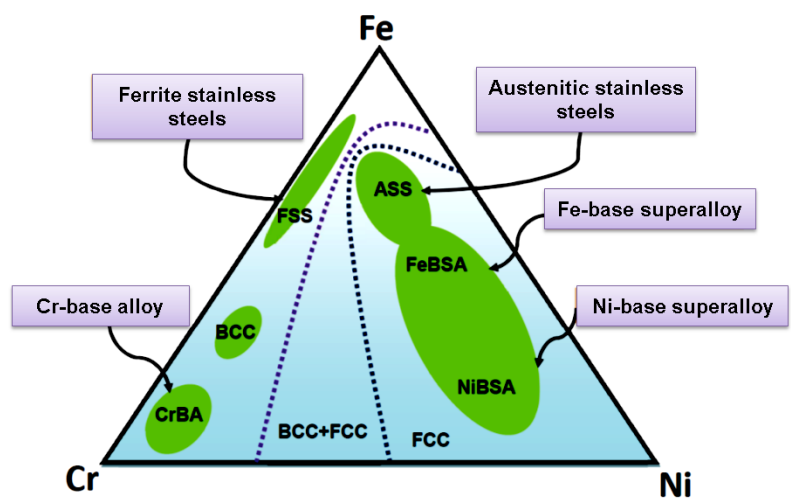

Figure 4. Nickel-based materials and their mechanical properties (Yang et al., 2002: p.11).

\section{Principles and methodology}

\subsection{Principles of cutting}

Machining is closely related to a machining station, cutting tools, jigs, and fixtures. The surface quality of workpiece and machining efficiency depend heavily on a number of factors, such as machining speed, feed rate, depth of cut, and width. Different machining conditions lead to different results. The influence is not only on the machining quality but also the effective time for the cutting tools to be available (Jaffery and Mativenga, 2012). When it comes to defining machining conditions, the cutting condition a numerical control (NC) design considers most are machining speed, depth of cut, feed rate, and width, among which the machining speed has the greatest influence on either surface accuracy or efficiency, as shown in Figure 5.

$$
V=\frac{\pi \times \phi D \times N}{1000}(\mathrm{~m} / \mathrm{min})
$$

Where $V=$ machining speed $(\mathrm{m} / \mathrm{min}), N=$ spindle rotation speed (rev/min), and $\phi D=$ cutter diameter $(\mathrm{mm})$.

Table 2. Chemical composition of Waspaloy.

\begin{tabular}{|c|c|c|c|c|c|c|c|c|c|c|c|}
\hline & $\mathrm{Cr}$ & $\mathrm{Ni}$ & $\mathrm{Co}$ & $\mathrm{Mo}$ & $\mathrm{W}$ & $\mathrm{Ti}$ & $\mathrm{Al}$ & $\mathrm{Fe}$ & $\mathrm{C}$ & $\mathrm{Nb}$ & Other \\
\hline Inconel-718 & 18 & $\mathrm{~B}$ & 0 & 2.8 & 0 & 1 & 0.5 & 18 & 0.025 & 5.4 & \\
\hline Waspaloy & 19.4 & $\mathrm{~B}$ & 13.3 & 4.3 & 0 & 3 & 1.5 & $2 \mathrm{Max}$ & 0.035 & 0 & \\
\hline
\end{tabular}


The machining efficiency can be improved by increasing the feed rate. However, it is learned from the empirical formula of surface accuracy that the surface accuracy is determined based on the feed rate and the tip radius of the cutter. As a result, an increase in the feed rate will make the surface of workpiece rougher.

$$
F=N \times T \times F_{z}(\mathrm{~mm} / \mathrm{min}) .
$$

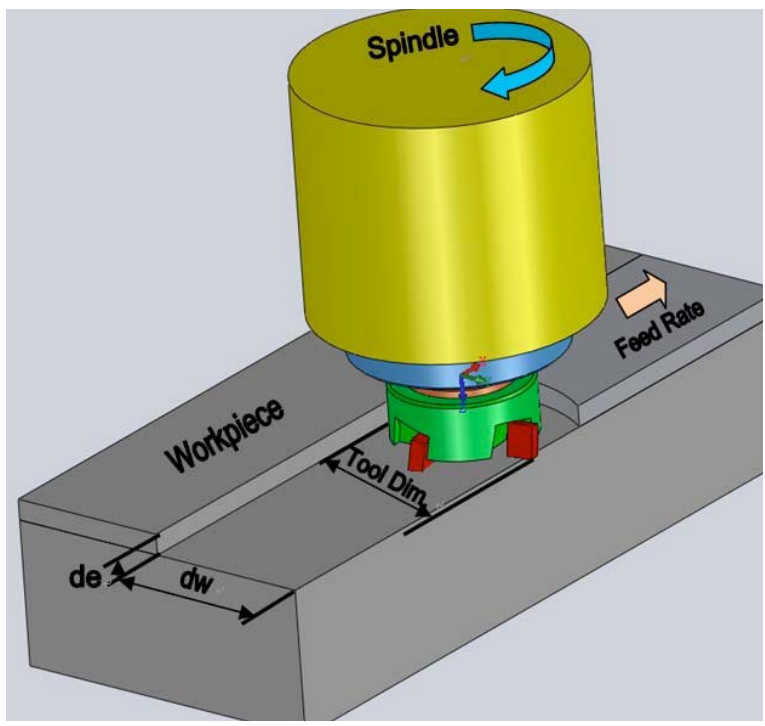

Figure 5. Machining parameters.

\subsection{Formula of cutter's service life}

Damage to a cutter is mostly in the form of wearing and breaking. Sequentially, the damage starts with wearing, which deteriorates into chipping and eventually large notches. The wears mostly come from:

1. The friction between metal shavings and the cutter's edge;

2. Accumulation of shavings on the built-up edge (BUE);

3. Friction due to a broken cutter's tip;

4. The abrasion resistance of tip and blade of a cutter at a high temperature; and

5. Diffusion that leads to cutter wears.

For breaking, the main causes are:

1. The cutter tip is not strong enough to resist cutting;

2. The cutter does not have enough ductility;

3. The base material is not able to be cut evenly; and

4. The cutting temperature causes the workpiece to harden and eventually the breaking of cutters.

To avoid wearing of cutters when dealing with aeronautical materials, it is necessary to consider excessive loading due to poor machining conditions or the breaking due to normal wearing. For the machining of nickel-based materials, hardening precipitation and diffusion affinity lead to premature wearing of cutters. The better the cutters are in heat resistance, the greater the $n$ value is (Chen and Ho, 2019; Hadzley et al., 2015; Ginta et al., 2009; MuñozSánchez et al., 2011). The tool wear is closely related to material removal rate which is proportional to feed rate, machining depth and width. Therefore, Taylor's formula for cutters can be revised as follows:

$$
V T^{n}=C .
$$

$$
\begin{aligned}
& \text { When } C=C^{\frac{1}{s}} F_{t}^{-\frac{e}{s}} d p^{-\frac{d}{s}} . \\
& \text { While } n=\frac{1}{s}, \\
& T=C^{\prime} V^{-s} F_{t}^{-e} d p^{-d},
\end{aligned}
$$

where $F_{t}$ is the workpiece or tool to feed rate, and $d p$ is the machining depth. It is found in the experiments that the tool life of cutters is most sensitive to the change of machining speed and least sensitive to the change of machining depth. Thus, with reference to Shaw (2002):

$$
s>e>d .
$$

In the experimental analysis with RSM, it is assumed that the input parameters that have influence on the response value, $y$, are $x_{1}, x_{2}, \ldots, x_{p}$, where $x$ is an independent variable, and the unknown function (dependent variable) is:

$$
y=f\left(x_{1}, x_{2}, . ., x_{p}\right)+\varepsilon .
$$

Where $\varepsilon$ is an error of the responsive variable $y$ (or experiment error). If the response to an expected value is expressed as $E(y)=f\left(x_{1}, x_{2}, \ldots, x_{p}\right)=\eta$ and the curved surface represented by $f$ is the response surface, then:

$$
\eta=f\left(x_{1}, x_{2}, . ., x_{p}\right)
$$

The constants $s, e$ and $d$ are determined based on experiment results, and the cutter service life prediction formula is established. A natural logarithm function applies to linearise the service life of cutters. Equation (4) is converted as:

$$
\ln T=\ln C^{\prime}+|s| \ln V+|e| \ln F_{t}+|d| \ln d p .
$$

When $x_{0}=1$, if the response can be mimicked by a linear function of an independent variable, the approximation function is called the first-order model, where $x_{1}, x_{2}$ and $x_{3}$ are log conversions of the machining 
speed, feed rate and depth of cut, respectively, and $\beta_{0}, \beta_{1}, \beta_{2}$ and $\beta_{3}$ are the parameters needed to be solved. The model is shown in Equation (9):

$$
y=\beta_{0}+\beta_{1} x_{1}+\beta_{2} x_{2}+\ldots+\beta_{p} x_{p}+\varepsilon .
$$

$y_{1}$ is the prediction response of the first-order regression model, which is proportional to the natural logarithm of the experiment result $y ; \varepsilon$ is the experiment error and $b$ is the predicted value corresponding to parameter $\beta$. The model is expressed as Equation (10):

$$
y_{1}=y-\varepsilon=b_{0}+b_{1} x_{1}+b_{2} x_{2}+b_{3} x_{3} .
$$

If a curvature exists in the prediction system for a cutter's service life, a polynomial of higher order, such as a multiple regression model, will be required. This approximation function of multiple regression model is mathematically expressed as:

$$
y=\beta_{0}+\sum_{i=1}^{p} \beta_{i} x_{i}+\sum_{i=1}^{p} \beta_{i i} x_{i}^{2}+\sum_{i<j} \sum \beta_{i j} x_{i} x_{j}+\varepsilon .
$$

\subsection{Experiment equipment and parameters}

\subsubsection{Experiment equipment}

The experiment setup was built around a combined machining station: Model VMP-40(A).

The experiment equipment is listed in Table 3 . The machining condition includes machining speed, depth of cut, and feed rate. A factor-and-level table was developed to obtain the largest number of useful data in the most economic and effective way before producing the optimised values through statistical concepts (Chen and Ho, 2019).

\subsubsection{Experiment parameter defining and process}

The parameters are defined in the following three steps (Chen and Ho, 2019).

\section{Step 1. Selection of experiment design}

This study was a total-factor design plus the features of centre point and axis point. It was a central composite design selected to improve the accuracy and correctness of the experiment.

Step 2. Establishment of experiment conditions

The primary significant factors were established for the examination of a cutter's tool life. Machining speed, feed rate, and depth of cut were selected for analysis and establishment. The centre position and axis position of $\alpha=1.633$ were added according to the design method. The experiment axis point factors and levels are shown in Table 4.

\section{Step 3. Experiment verification}

Several cutting experiments were conducted for the analysis of the wearing of cutters. Total-factor design and a central composite design (CCD) were applied for the arrangement of matrix. The conversion function is as follows:

$$
x_{1}=\frac{\ln V-\ln 35}{\ln 40-\ln 35} ; x_{2}=\frac{\ln F_{t}-\ln 0.2}{\ln 0.3-\ln 0.2} ; x_{3}=\frac{\ln d p-\ln 0.2}{\ln 0.3-\ln 0.2}
$$

Table 3. Experiment equipment.

\begin{tabular}{|l|l|}
\hline \multicolumn{1}{|c|}{ Equipment name } & \multicolumn{1}{|c|}{ Specifications and mode } \\
\hline $\begin{array}{l}\text { Machining station } \\
\text { VMP-40(A) }\end{array}$ & $\begin{array}{l}\mathrm{X} / \mathrm{Y} / \mathrm{Z} \text {-axis travel: } \\
1,020 \mathrm{~mm} / 520 \mathrm{~mm} / 505 \mathrm{~mm} \\
\text { Max rpm: } 10,000 \mathrm{rpm}\end{array}$ \\
\hline $\begin{array}{l}\text { Square milling cutter } \\
\text { RCKT1204M-MM2040) }\end{array}$ & $\begin{array}{l}\text { Cutter's dia.: } 12 \mathrm{~mm} \\
\text { (Cutter's R angle: } 6 \mathrm{~mm})\end{array}$ \\
\hline
\end{tabular}

Table 4. Independent variables with levels and coding identification (Chen and Ho, 2019: p.10).

\begin{tabular}{|l|c|c|c|c|c|}
\hline \multicolumn{1}{|c|}{ Factor } & $\begin{array}{c}\mathbf{- 1 . 6 3 3} \\
\text { (lowest) }\end{array}$ & $\begin{array}{c}\mathbf{- 1} \\
\text { (low) }\end{array}$ & $\begin{array}{c}\mathbf{0} \\
\text { (Centre) }\end{array}$ & $\begin{array}{c}+\mathbf{1} \\
\text { (high) }\end{array}$ & $\begin{array}{c}+\mathbf{1 . 6 3 3} \\
\text { (highest) }\end{array}$ \\
\hline Machining speed (m/min) & 26.835 & 30 & 35 & 40 & 43.165 \\
\hline Depth of cut $(\mathrm{mm})$ & 0.0367 & 0.1 & 0.2 & 0.3 & 0.3633 \\
\hline Feed per tooth $(\mathrm{mm} / \mathrm{t})$ & 0.0367 & 0.1 & 0.2 & 0.3 & 0.3633 \\
\hline
\end{tabular}


When the response surface is moving away from the best condition position, there is only little curvature in the system, and the first order model is appropriate. The objective is to move to an approximate value as close to the best-fit value as possible. This is when the method of the steepest ascent comes into play. The steepest ascent works by moving along the largest responsive variable. Once it approaches the best-fit point, a multiple regression model is introduced to identify the best-fit point. In general, the method of a CCD is used. A CCD is a two-level total or partial factor design for amplification with little processing which makes the estimation with a multiple regression response surface model possible.

\section{Results and discussions}

The study was designed to analyse the relationship between machining parameters and cutter wearing for the machining of Waspaloy, as shown in Figure 6. A regression analysis was applied for the establishment of the relationship with cutters' service life. Observation was made for various machining parameters. It can be seen from the figures that the wearing of cutters increases with the feed rate per tooth and depth of machining by fixing the machining speed at $V c=30 \mathrm{~m} / \mathrm{min}$. In addition, the wearing increases when the feed rate and depth of cut are fixed, and the machining speed increases from $V_{c}=30 \mathrm{~m} / \mathrm{min}$ to $V_{c}=$ $43 \mathrm{~m} / \mathrm{min}$.

\subsection{First-order model of tool life}

The variable factors in the first-order model of cutters' service life were the machining speed, feed rate per tooth, and depth of cut. During the machining process of Waspaloy, the depth of cut had a marginal influence on the wearing of cutters. A factor was considered significant with the P-value $<0.05$. The machining speed, feed per tooth, and depth of cut were all significant factors, as shown in Table 5. For $\mathrm{P}=0.1$ in the partial F-test, where the variables were fixed in the goodness-of-fit test, it was clear that this model was fit for prediction and lacked fitness where $\mathrm{P}>$ $\alpha=0.05$. When the test coefficient $\mathrm{R}^{2}=72.41 \%$, the test coefficients were low, indicating that the first-order model was not appropriate and therefore a multiple regression model existed. By adding axis points to the multiple regression model, the analysis of the variance on the multiple regression model was conducted in the following steps. model:

The prediction function for the first-order regression

$$
y_{1}=-0.209+0.11 V+0.76 d p+0.378 F_{t} \text {. }
$$
life:

The first-order prediction equation for cutters' service

$$
T=1.695 V^{-0.8217} d p^{-0.763} F t^{-0.835} .
$$

The analysis was done by using coded units.

Table 5. First-order regression.

\begin{tabular}{|l|c|c|c|c|}
\hline \multicolumn{5}{|c|}{ Estimated regression coefficients for Wear 1 } \\
\hline Term & Coef & SE Coef & $T$ & $P$ \\
\hline Constant & 0.349762 & 0.01480 & 23.625 & 0.000 \\
\hline Block & 0.004762 & 0.01480 & 0.322 & 0.755 \\
\hline$V(\mathrm{~m} / \mathrm{min})$ & 0.058256 & 0.01635 & 3.563 & 0.006 \\
\hline$d p(\mathrm{~mm})$ & 0.037660 & 0.01635 & 2.303 & 0.047 \\
\hline$F t(\mathrm{~mm} /$ tooth $)$ & 0.037818 & 0.01770 & 2.136 & 0.061 \\
\hline $\mathrm{S}=0.0513856$ & PRESS $=0.0627552$ \\
$\mathrm{R}-\mathrm{Sq}=72.41 \%$ & R-Sq(pred $)=27.15 \%$ & $\mathrm{R}-\mathrm{Sq}(\mathrm{adj})=60.15 \%$ \\
\hline
\end{tabular}

\subsection{Multiple regression model of tool life}

The key to observe in the multiple regression model was the linearity and whether the P-value in the multiple regression and interaction models had any influence on the cutter service life prediction model. For the factor combinations and number of levels in the multiple regression model, the best-fit multiple regression model is expressed as follows:

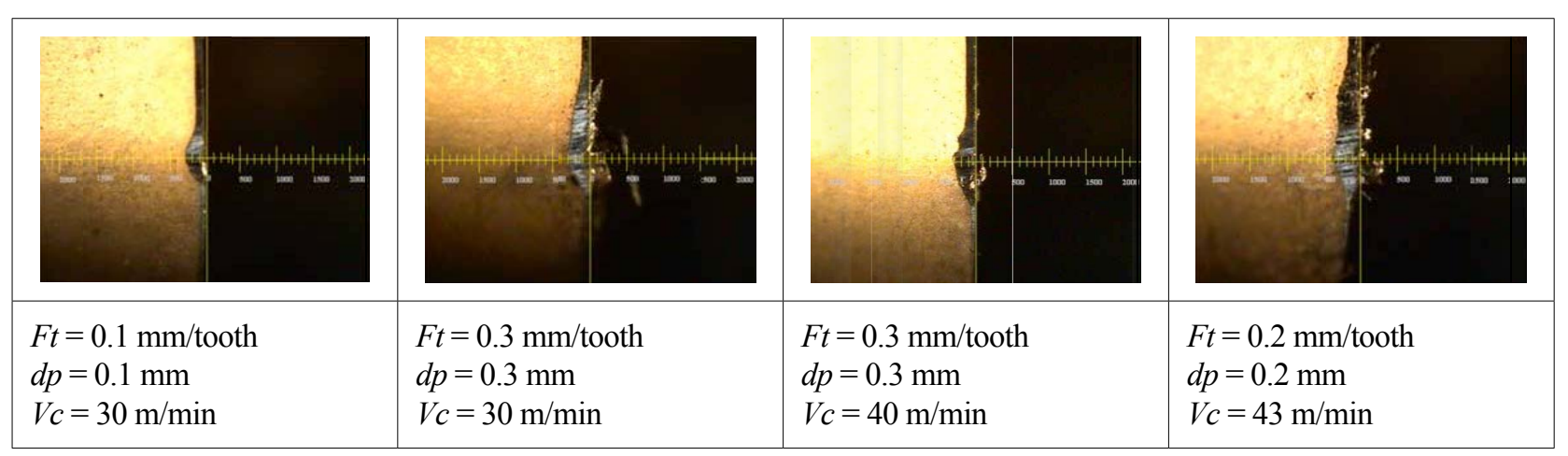

Figure 6. Different machining parameters and tool wear. 


$$
y=\beta_{0}+\sum_{i=1}^{p} \beta_{i} x_{i}+\sum_{i=1}^{p} \beta_{i i} x_{i}^{2}+\sum_{i<j} \sum \beta_{i j} x_{i} x_{j}+\varepsilon .
$$

For the lack-of-fit test for the second order model, the T-test is applied to check the significance of individual regression coefficients on the multiple linear regression model.

$$
\begin{aligned}
& H_{0}: \beta_{1}=\beta_{2}=\ldots \ldots \ldots=\beta_{i}=\beta_{j}=\beta_{i j}=0, \\
& H_{1}: \beta_{i} ; \beta_{j} ; \beta_{i j} \neq 0 \quad \text { For at least one } i j .
\end{aligned}
$$

First, the levels of all factors were combined for analysis. The analysis of variance indicated P-Value $=0.096$ for interaction. Therefore, some factors in the interaction model were not significant. The test coefficient $\mathrm{R}^{2}=$ $93.17 \%$, suggests the test coefficient should be very close to $100 \%$ and therefore fitted the multiple regression model. For the lack-of-fit test where the variables were fixed in the goodness-of-fit test, $\mathrm{P}=0$ in the lack-of-fit test suggested that the experiment values be concentrated. As a result, two insignificant factors, $V^{*} d p$ and $d p^{*} F t$, were removed from the interaction model for another analysis because the test coefficient P-Value $>0.05$.

When the interaction is out of the equation, a test coefficient of $\mathrm{R}^{2}=90.88 \%$ was observed in the regression analysis table as shown in Table 6, indicating it was fit for the multiple regression model. A factor was considered significant when $\mathrm{P}$-value $<0.05$, and that was the case for machining speed, feed rate per tooth and depth of cut. For the lack-of-fit test, $\mathrm{P}=0.142$, which was greater than $\alpha=0.05$ with no refusal of the null hypothesis. For F-test, a goodness-of-fit test was conducted on the multiple regression model. By substituting the value into the equation, the equation of judgment is expressed as follows:

$$
F=\frac{[0.008569-0.006423] / 4}{0.006423 / 7}=0.585,
$$

$$
F=\frac{0.000022}{0.000050}=0.44<F_{(0.05,4,7)}=0.585 \text {. }
$$

It was found in the F-test that $F<F_{(\alpha, m-p, n-m)}$ and therefore there is no refusal for null hypothesis. The analysis of variance suggested that the results were good. The insignificant interaction and multiple regression terms were removed. Therefore, axis points were added and the analysis of variance was carried out for the multiple regression model. The following is the prediction equation for the multiple regression model:

$$
y_{1}=0.401-0.011 V-1.64 d p-1.516 F_{t}+3.12 d p^{2} .
$$

\subsection{Prediction of minimum wear}

A residual analysis was conducted on the established regression model for a better accuracy of the prediction of cutter service life and to test whether the regression model was appropriate. The results of the residual analysis are shown in Figure 7. It is clear that no violation of the hypotheses is found in the trends of the diagram, indicating that the model meets the hypotheses.

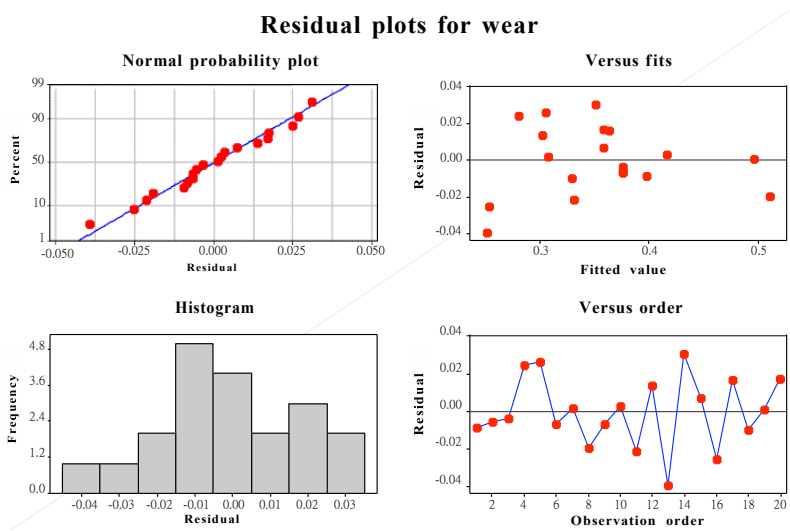

Figure 7. Residual analysis.

Table 6. Multiple regression.

\begin{tabular}{|c|c|c|c|c|}
\hline Term & Coef & SE Coef & $T$ & $P$ \\
\hline Constant & 0.367539 & 0.011422 & 32.179 & 0.000 \\
\hline Block & 0.009000 & 0.006370 & 1.413 & 0.185 \\
\hline$V(\mathrm{~m} / \mathrm{min})$ & 0.051275 & 0.007644 & 6.708 & 0.000 \\
\hline$d p(\mathrm{~mm})$ & 0.030496 & 0.007644 & 3.990 & 0.002 \\
\hline$F t(\mathrm{~mm} /$ tooth $)$ & 0.033691 & 0.007644 & 4.408 & 0.001 \\
\hline$V(\mathrm{~m} / \mathrm{min}) * V(\mathrm{~m} / \mathrm{min})$ & 0.020481 & 0.007680 & 2.667 & 0.022 \\
\hline$d p(\mathrm{~mm}) * d p(\mathrm{~mm})$ & -0.021519 & 0.007680 & -2.802 & 0.017 \\
\hline$F t(\mathrm{~mm} /$ tooth $) * F t(\mathrm{~mm} /$ tooth $)$ & -0.018894 & 0.007680 & -2.460 & 0.032 \\
\hline$V(\mathrm{~m} / \mathrm{min}) * F t(\mathrm{~mm} /$ tooth $)$ & 0.022375 & 0.009868 & 2.267 & 0.045 \\
\hline $\mathrm{S}=0.0279103 \quad \mathrm{PRESS}=0.0491261$ & & & \\
$\mathrm{R}-\mathrm{Sq}=90.88 \% \quad \mathrm{R}-\mathrm{Sq}(\mathrm{pred})=47.74 \%$ & $\mathrm{R}-\mathrm{Sq}(\mathrm{adj})=84.25$ & \\
\hline
\end{tabular}


The simplest way to determine whether the stability point is the maximum, minimum or saddle point and increment (or decrement) is to use the fitted model to plot the contour diagrams and response curves in order to establish an optimised area. The minimum cutter wear can be identified using appropriate parameters. The contour diagrams from the multiple regression equation for the cutter service life is shown in Figure 8. It is known from the machining speed versus depth of cut that the minimum wear area is located at $V=30 \mathrm{~m} / \mathrm{min}-32 \mathrm{~m} / \mathrm{min}$ and below $d p=0.05 \mathrm{~mm}$. The smaller the cutting depth is, the less the cutter is worn. For machining speed versus feed per tooth, the minimum wear area is located at $V=28 \mathrm{~m} / \mathrm{min}$ $40 \mathrm{~m} / \mathrm{min}$ and below $F t=0.1 \mathrm{~mm} /$ tooth.
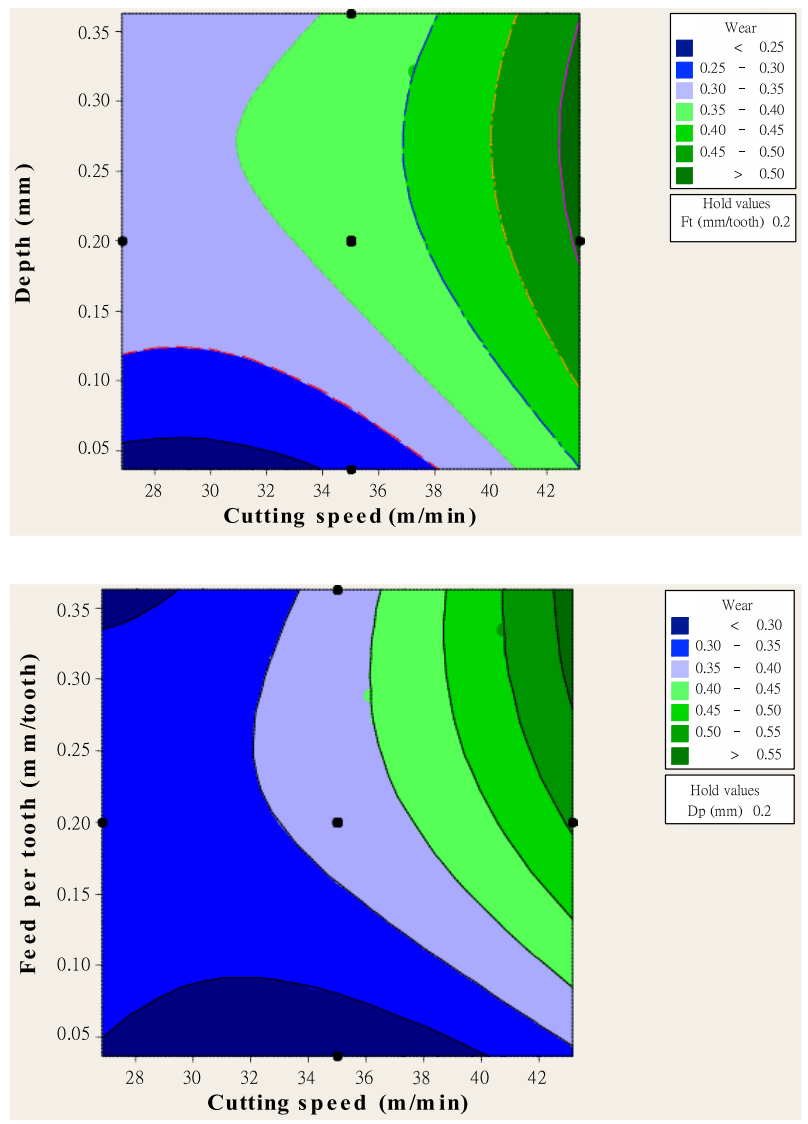

Figure 8. Contour diagram and response surface.

The analysis predicts the minimum wear of cutter with machining speed at $V=33.21 \mathrm{~m} / \mathrm{min}$, depth of cut at $d p=$ $0.0367 \mathrm{~mm}$ and feed per tooth at $F t=0.0367 \mathrm{~mm} /$ tooth. As a result, for machining for a long period of time, medium or accurate machining should be carried out based on the minimum cutter wear for the ideal condition of cutter service life, as shown in Figure 9. The theoretical prediction value of the cutter wear in the verification experiment was $W=0.1523 \mathrm{~mm}$ as shown in Figure 10, and the cutter wear recorded in the experiment was $W=0.136 \mathrm{~mm}$ $0.175 \mathrm{~mm}$, indicating an error of less than $15 \%$.

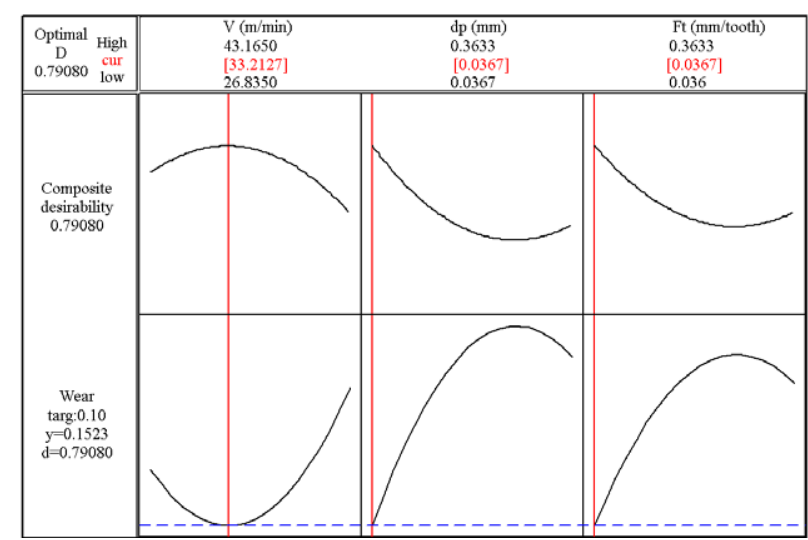

Figure 9. Minimum wear prediction for cutters.
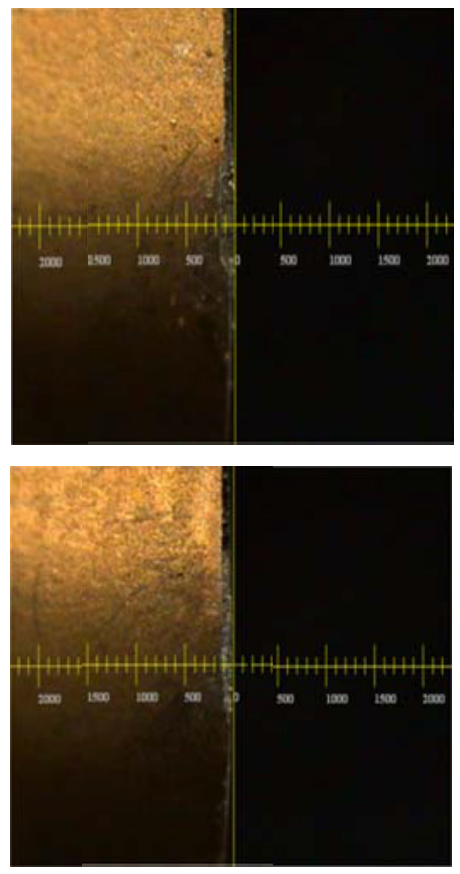

Figure 10. Verification of cutter wear.

\section{Conclusion}

The primary factors of the influences on cutter wear are machining speed, depth of cut and feed rate per tooth for the machining of Waspaloy, a nickel-based material. A regression analysis suggests that machining speed should have the largest influence on wear. Excessive cutting temperature results in hardening precipitation and the affinity of cutters leads to premature breaking of cutters.

The first-order machining prediction experiment suggests low test coefficients probably because the wear of cutter during the experiments was too small to allow immediate response and prediction. This in turn results in too small the result of judgment and an easy production of prediction errors. However, the accuracy improves dramatically in the multiple regression experiments, 
indicating that cutter wear is nonlinear in most cases.

A multi-variable prediction formula was used in this study. The theoretical prediction for cutter wear in the verification experiment was $W=0.1523 \mathrm{~mm}$, whereas the cutter wear after the experiment was $W=0.136 \mathrm{~mm}$ $0.175 \mathrm{~mm}$. The error is less than $15 \%$. For the machining of nickel-based material, the material itself is a key variable which may easily lead to premature wearing and breaking of cutting tools. Therefore, it is included in the prediction formula as one of the important variables.

For the same cutting process, the machining speed at $V=33.21 \mathrm{~m} / \mathrm{min}$, depth of cut at $d p=0.0367 \mathrm{~mm}$ and feed rate per tooth at $F t=0.367 \mathrm{~mm} /$ tooth provide a prediction of minimum wear of cutters.

\section{Notes on Contributors}

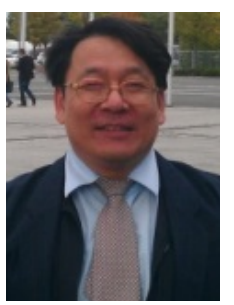

Dr Shao-Hsien Chen received his Ph.D. degree in Mechanical Engineering from National Chung Cheng University (NCCU), Taiwan in 2006. His current researches focus on Computer Numerical Control (CNC) machine tool design for mill machine and lathe machine, $\mathrm{CNC}$ machine tool assembly technology, CNC machine tool application technology and intelligent and smart manufacturing.

He had been working at AWEA Corporation, Ching Hung Machinery \& Electric Industrial Corporation and Precision Machinery Research Development Center. He has over 17 years' experiences working in the industry. Now, he is an Assistant Professor at the Department of Mechanical Engineering of National Chin-Yi University of Technology (NCUT) in Taiwan.

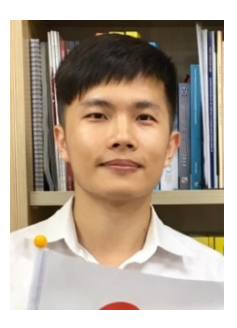

Mr Yu Lun Ho received his master's degree in the Department of Mechanical Engineering at NCUT in 2015. His current researches focus on $\mathrm{CNC}$ machine tool application technology and intelligent and smart manufacturing. Now, he is working as an Engineer at Litz Hitech Corporation in Taiwan.

\section{References}

[1] Akhtar W, Sun J, Sun P, Chen W and Saleem Z (2014). Tool wear mechanisms in the machining of nickel based super-alloys: A review. Frontiers of Mechanical Engineering, 9(2), pp. 106-119.

[2] Aucote J and Foster S R(1986). Performance of sialon cutting tools when machining nickel-base aerospace alloys. Materials Science and Technology, 2(7), pp. 700-708.
[3] Bhadeshia H K D H (2012). Nickel based superalloys. Cambridge: University Of Cambridge.

[4] Bhatt A, Attia H, Vargas R and Thomson V (2010). Wear mechanisms of WC coated and uncoated tools in finish turning of Inconel 718. Tribology International, 43(5-6), pp. 1113-1121.

[5] Carpenter Technology Corporation (2009). Selection of age-hardenable superalloys. United States: Carpenter Technology Corporation.

[6] Che-Haron C H, Ginting A and Goh J H (2001). Wear of coated and uncoated carbides in turning tool steel. Journal of Materials Processing Technology, 116, pp. 49-54.

[7] Chen S H and Ho Y L (2019). Lifespan of super-alloy Waspaloy cutting tools. Heliyon, 5(4), e01388.

[8] Chomsamutr K and Jongprasithporn S (2012). Optimization parameters of tool life model using the taguchi approach and response surface methodology. International Journal of Computer Science, 9(1), No 3, pp. 120-125.

[9] Ginta T L, Nurul Amin A K M, Mohd Radzi H C D and Lajis M A (2009). Tool life prediction by response surface methodology in end milling titanium alloy Ti-6Al-4V using uncoated wc-co inserts. European Journal of Scientific Research, 28(4), pp. 533-541.

[10] Hadzley A B, Izamshah R, Shahir K M, Amra A M and Afuza A (2016). Response surface methodology approach on effect of cutting parameter on tool wear during end milling of high thermal conductivity steel -150 (HTCS-150). Materials Science and Engineering, 114, 012015.

[11] Hadzley M, Sarah S, Izamshah R and Fatin N (2015). The study of tool wear performance on pecket milling strategy. Applied Mechanics and Materials, 699, pp. 64-69.

[12] Haldipur P and Bruce R (2006). Material characterization of nickel-based superalloys through ultrasonic inspection. United States: Iowa State University.

[13] Haldipur P, Margetan F J and Thompson R B (2003). Correlation between local ultrasonic properties and grain size within jet-engine nickel alloy billets. AIP Conference Proceedings, 657, pp. 1355.

[14] Jaffery S H I and Mativenga P T (2012). Wear mechanisms analysis for turning Ti-6Al-4Vtowards the development of suitable tool coatings. International Journal of Advanced Manufacturing Technology, 58, pp. 479-493.

[15] Kear B H, Oblak J M and Giamei A F (1970). Stacking faults in gamma prime $\mathrm{Ni}_{3}(\mathrm{Al}, \mathrm{Ti})$ precipitation hardened nickel-base alloys. Metallurgical and Materials, pp. 2477-2486.

[16] Komanduri R and Schroeder T A (1986). On shear instability in machining a nickel-iron base superalloy. Journal of Manufacturing Science and Engineering (ASME), 108(2), pp. 93-100. 
[17] Li A, Roberts R, Haldipur P, Margetan F J and Thompson R B (2003). Computational study of grain scattering effects in ultrasonic measurements. AIP Conference Proceedings, 657, pp. 117.

[18] McDevitt E T (2013). Nickel-base alloy heat treatments, nickel-base alloys, and articles including nickel-base alloys. Patent No. US20130133793 A1.

[19] Muñoz-Sánchez A, Canteli J A, Cantero J L and Miguélez M H (2011). Numerical analysis of the tool wear effect in the machining induced residual. Simulation Modelling Practice and Theory, 19(2), pp. 872-886.

[20] Obikawa T, Yamaguchi M, Funai K, Kamata Y and Yamada S (2012). Air jet assisted machining of nickelbase superalloy. International Journal of Machine Tools \& Manufacture, 61(C), pp. 20-26.

[21] Ozturk U, Cabrera J M and Calvo J (2016). Hightemperature deformation of inconel 718Plus TM. Journal of Engineering for Gas Turbines and Power, 139(3), pp. 1-7.

[22] Reddy B S, Kumar J S and Reddy K V K (2011). Optimization of surface roughness in $\mathrm{CNC}$ end milling using response surface methodology and genetic algorithm. International Journal of Engineering, Science and Technology, 3(8), pp. 102109.

[23] Saedon J B, Soo S L, Aspinwall D K, Barnacle A and Saad N H (2012). Prediction and optimization of tool life in micro milling AISI D2 ( 62 HRC) hardened steel. Procedia Engineering, 41, pp. 1674-1683.

[24] Shaw M C (2002). Metal cutting principle. Oxford: Oxford Series on Advanced Manufacturing. pp. 20.

[25] Sims C T and Hagel W (1972). The superalloys. New York:Wiley Interscience. pp. 12.

[26] Stanke F E and Kino G S (1984). A unified theory for elastic wave propagation in polycrystalline materials. The Journal of the Acoustical Society of America, 75(3), pp. 665.

[27] Thangaraj A R and Weinmann K J (1992). On the wear mechanisms and cutting performance of silicon carbide whisker-reinforced alumina. Journal of Manufacturing Science and Engineering, 114(3), pp. 301-308.

[28] Turnad L, Ginta A K M, Nurul A, Karim A N M, Patwari A U and Lajis M A (2008). Modeling and optimization of tool life and surface roughness for end milling titanium alloy Ti-6Al-4V using uncoated $W C$-Co inserts. In: Proceedings of the CUTSE International Conference. [online]. Malaysia: UTHM Institutional Repository. Available at: $<$ http://eprints. uthm.edu.my/id/eprint/184/1/turnad_1._ginta_2.pdf $>$. [Accessed on 24-27 Nov. 2008].
[29] Wagner V, Baili M and Dessein G (2014). The relationship between the cutting speed, tool wear, and chip formation during Ti-5553 dry cutting. The International Journal of Advanced Manufacturing Technology, 76, pp. 893-912.

[30] Xue C and Chen W (2011). Adhering layer formation and its effect on the wear of coated carbide tools during turning of a nickel-based alloy. Wear, 270(1112), pp. 895-902.

[31] Yang Z G, Paxton D M, Weil K S, Stevenson J W and Singh P (2002). Materials properties database for selection of high-temperature alloys and concepts of alloy design for SOFC applications. Washington: Pacific Northwest National Laboratory Richland. pp. 11. 